\title{
The Application of Green Accounting According to Activity-Based Costing for an Orientation Towards a Green Economy:
}

\section{Field Study}

\author{
Zakaria Demdoum, University of Eloued, Algeria \\ Oualid Meraghni, University of Eloued, Algeria \\ Latifa Bekkouche, University of Eloued, Algeria
}

\begin{abstract}
The present study aims to identify the opportunities and possibilities for applying green accounting according to the activity-based costing in light of the trend towards a green economy. To achieve this aim, the researchers designed and administered a questionnaire. A random sample of 180 individuals (participants) from managers and accountants of economic institutions in the southeastern area in Algeria are selected, and the statistical program SPSS 22 is used to analyze the obtained data. The study found that the sample institutions have a low level of interest in the environmental dimension, as well as a low level of interest in measuring environmental costs, which requires increased pressures on these organizations, whether from the government side or from the consumers.
\end{abstract}

\section{KEYWORDS}

Activity-Based Costing, Environmental Cost Drivers, Green Accounting, Green Economy

\section{INTRODUCTION}

Sustainability contains three interconnected and overlapped pillars; they are environmental, social and economic parts (Rounaghi, 2019). The United Nations conference on the environment and development, held in Rio de Janeiro in 1992, formally adopted the concept of sustainable development that is defined by the Brundtland report as a "development that meets the needs of the present without compromising the ability of future generations to meet their own needs". Twenty years later, the Rio+20 conference coined the concept "green economy". This popular concept is perceived as a pathway to sustainability by international organizations such as The World Bank (2012) and the United Nations Environment Programme (Loiseau \& all, 2016).

Emerging from the field of environmental economics, the concept of a green economy became the centerpiece of the Rio+20, launching the green economy as the new buzzword in discussion related to sustainable development. In its simplest terms, the green economy is low-carbon, resource efficient and socially inclusive, revenue and job growth are powered by public and private investment 
that decreases carbon emissions and pollution, increases energy and resource efficiency, and avoids biodiversity and ecosystem services losses (Vuola \& Korkeakoski, 2020).

For green economy, Green accounting is an important concept (Unnithan \& Somasundaram, 2019). Green accounting is a type of accounting that attempts to factor environmental costs into the

financial results of operations (Rounaghi, 2019). It has been argued that Gross domestic product disregards the environment and thus policymakers need a revised model that integrates green accounting (Sachin \& Sandeep, 2019). It is a path for intellectual expansion of accounting. By means of this tool, the proper decision making and the introduction of greener technology will reduce many of the environmental costs. It plays a very important role in the Corporate Social Responsibility (CSR) of a firm and also plays a vital role in decision making of the firm regarding the methods or procedure used and, consequently, the profitability of the enterprise. The government should take strict penalties for those who do not adhere to environmental standards, and organizations should take an initiative to implement green accounting in all the levels of the organization (Agarwal \& Kalpaja, 2018).

Green accounting or environmental accounting is interlinked with two basic functions of management accounting: planning, and data collection and reporting. In the case of planning, green accounting uses prevision analysis to measure future impacts on environment. In the second case, environmental data collection and its reporting to management is based on an efficient analysis of data for substantiating decisions (Stoicea, 2012).

In recent years, managers have begun to embrace activity-based costing; ABC (Rimer, 2000) as an efficient management accounting tool that identifies the true production costs and provides an incentive to improve continuing processes in the company or even re-engineering that is not necessarily established through traditional accounting systems (Van Der Poll, 2014). ABC is a method of evolving cost estimates in which the project is subdivided into discrete, a quantifiable work unit or activities that must be defined in order that productivity can be measured in units. A cost estimates for each operation is prepared after the project is broken down into its activities. For each activity, this individual cost estimates would include all costs of labor, materials, equipment, and subcontracting including overhead. To obtain an overall estimate, each complete individual estimate is added to the others. Contingency and escalation can be calculated for each activity or after all the activities have been summed (Bogdănoiu, 2009).

Within the above mentioned framework, this research falls under the uses of the activity-based costing method; furthermore, it seeks to find a language that helps to facilitate the understanding of the new terms or concepts used by green accounting for the purposes of internal uses of enterprises. The green economy, which encourages environmental protection, social inclusiveness and economic growth at the same time, is expected to help the least developed countries that are heavily resourcedependent (Vuola \& Korkeakoski, 2020). Therefore, this study is conducted in Algeria as one of those countries to tackle the following main research question:

What is the reality of interest in applying green accounting according to the ABC method in light of the trend towards a green economy?

And the following sub-questions:

How to build a model for applying the $\mathrm{ABC}$ method while adopting green accounting?

To what extent do business organizations pay attention to the environmental dimension in the Algerian environment?

How interested are business organizations in measuring green costs in the Algerian environment?

The importance of this study stems from the extent to which the institution knows how to implement green cost accounting according to the $\mathrm{ABC}$ method in light of adopting green accounting and following up on what it receives from the environment and what it reciprocate, through green accounting information systems. It would help in the effective use of resources and the reduction of pollution to some extent. 
This study aims to:

- get acquainted with the theoretical rooting of green accounting.

- Harmonize the ABC cost method in institutions that support the environmental dimension.

- And analyze the business organizations' perception of the importance of green accounting as a means that helps the promotion of green and environmental economies.

To address the topic of our research and its various aspects, we relied on the descriptive approach to build the theoretical framework for the concept of green accounting, and on the analytical approach to tackle the applied aspect. The study is limited to the opinions of accountants and those charged with conducting accounting business who work in economic institutions, most of which were small and medium enterprises operating in the southeast of Algeria. The content and results of the study are related to the time in which the study was conducted (the first semester of 2020). To surround the topic of the study in some detail, it is dealt with as follows:

First: The theoretical framework for applying green accounting according to the ABC method. Second: the field study and discussion of the results.

\section{THEORETICAL FRAMEWORK}

\section{$A B C$ and Green Accounting}

The green economy is defined as an economy that aims for sustainable development without degrading the environment by reducing environmental risks and ecological scarcities. It is closely related with ecological economics, but has a more politically applied focus (Shukla \& Bhamre, 2017). The 2011 UNEP Green Economy Report contends that to be green, an economy must not only be efficient but also fair. Justice implies recognition of equity dimensions at global and country level, especially in ensuring a just transition to a low-carbon, resource-efficient and socially inclusive economy (Rahmane $\&$ all, 2019).

The green economy needs new business models and new concepts such as the company's responsibility for the environment that is called CSR (Ryszawska, 2019). CSR is about the ways an entrepreneur can add value to their business by looking more closely at some of the social and environmental aspects of operational activities they carried out. The CSR of a company demonstrated through transparent and accountable disclosure of information to the public. Accounting should disclose information to corporate stakeholders as business language. When a company starts a green movement as part of its responsibility for the environment, the term of Green accounting is born (Pramitari \& all, 2019). The Green Accounting term was first introduced into usual utilization by Economist and Professor Peter Wood in the 1980s (Unnithan \& Somasundaram, 2019). Green accounting is a type of accounting that can provide information about how much the environmental costs that must be spent by the company to produce products or services that are environmentally friendly (Pramitari \& all, 2019). The implication of implementing green accounting by companies means that the company has supported sustainable development and green economy. It will certainly improve the good image of the company in the community and other stakeholders because of the importance of environmental-based accounting (Abdullah \& Yuliana, 2018).

Green Accounting uses the System of Environmental Economic Accounting (SEEA), which concentrates on the depletion of limited natural resources and estimates the cost of environmental degradation and its prevention (Sinha, 2020). Renewable resources can be used repeatedly and replaced naturally without emission of toxic gases (Aruna \& Venkataswamy, 2018), but non-renewable resources once consumed are gone forever and cannot be replaced (Steven \& Hines, 1985). Green accounting's key aim is to help organizations consider and handle the possible quid pro quo between conventional 
economic objectives and environmental objectives. It also increases the critical information available for policy issues to be examined, especially because these crucial pieces of information are often ignored. Green accounting only ensures weak sustainability, which should be considered as a step toward ultimately a strong sustainability (Rajshree \& Vangara).

There are two aims of green accounting, one of which is to enhance the company's financial and environmental efficiency and the other is to verify how the organization has an effect on the environmental system. The incorporation of green accounting in the organization's management system is essential for the advancement of the organization's environmental and economic performance. Yet, it is still a difficult task to implement this type of accounting in a number of countries due to the stakeholders' lack of information regarding the additional cost expenditure and implementation effects (Vijayalakshmi \& all, 2019).

When companies make their final accounts or their balance sheets, green accounting is a road to a sustainable future; they typically consider the internal costs such as labor costs and material costs that directly impact the organization's balance sheet. Sometimes, external costs such as environmental, social, and economic costs are overlooked. The organization must verify that external factors are also taken into account in order to be able to use scarce resources cautiously and efficiently. Green accounting can be used by the company as a method to keep track of all the activities from which the company profits from the environment, to keep an account of what it has been done to give something back to the environment in return of what it has been gotten, and evaluate the data as to what steps need to be taken to save the ecosystem that is ultimately being depleted (Agarwal \& Kalpaja, 2018).

The aim of green accounting is the acknowledgement and attempt to identify ways of diminishing the negative effects of activities and systems on the environment. The object of green accounting consists mainly in the identification and measuring of raw material costs and environmentally specific activities and the use of this information for drawing up reports and internal analyses necessary to the company management for making environmental decisions (Capusneanu, 2008).

Activity Based Costing ( $\mathrm{ABC}$ ) is one creative costing approach intended to cope with the limitations in conventional costing systems. ABC, pioneered by Robert Kaplan, Robin Cooper and $\mathrm{H}$. Thomas Johnson, is a costing technique used explicitly to trace overhead costs directly to cost objects, i.e. products, processes, services, or customers, and to help managers to make the right decisions regarding product mix and competitive strategies. Cooper describes two stages in the ABC model. Costs are allocated to cost pools inside an activity center in the first stage, based on a cost driver. In a traditional costing process, there is no equivalent step. At the second level, costs are assigned to a product from the cost pools based on the consumption of activities by the product. This step is similar to the traditional costing approach, with the exception that the traditional approach uses the product's volume-related characteristics strictly without regard to non-volume-related characteristics. Setup hours, number of setups, ordering hours, and number of orders are some examples of cost drivers that are unrelated to volume. Allocating non-volume related costs using volume-based methods distort the product costs (Roztocki \& all 2004).

Broadly speaking, ABC is an approach for allocating overhead costs, and more precisely, it allocates overhead to multiple cost pools of activity and then assigns cost pools of activity to products and services through cost drivers. In other words, some meanings are applied to words that make up the definition: In activity-based costing, an activity is any event, action, transaction, or a sequence of work that suffers costs when making a product or supplying a service. The overhead cost attributed to a special type of activity (e.g., ordering materials or setting up machines) is an activity cost pool. Any factor or activity which has a direct cause-effect relationship with the resources consumed is a cost driver. The reasoning behind the allocation of costs with $\mathrm{ABC}$ is simple: consumption of products, activities, and activities consume resources. ABC allocates overhead in a two-stage process (Weygandt $\&$ all, 2018) which produce Activity-based information.

According to Turney, $\mathrm{ABC}$ model contains two types of information to improve decision making: cost information and process information. Cost information explains the cost of work and its use, 
whereas Process information explains why the work is done and how well it is performed, and it describes relationships with customers and suppliers. Each type of information has a defined role in the continuous improvement process. This is called the two-dimensional model. This fact-based process uses activity-based information to describe the work and its results. It applies this information to a wide variety of strategic and tactical issues such as what price to set, what product mix to sell, and which improvements to make (Turney, 1992).

Activity based management (ABM) refers to the use of the basic information provided by $\mathrm{ABC}$ analysis to help managers to ensure that customer needs are satisfied with the minimal use of organizational resources (Avis \& all, 2009). It refers to the entire set of procedures that can be done with activity-based cost information, on a better informed basis. With ABM, the organization accomplishes its outcomes with fewer demands on organizational resources; that is, the organization can achieve the same outcomes (e.g., revenues) at a lower total cost (lower spending on organizational resources) (Kaplan \& Cooper, 1998).

The accounting can help companies by using ABC to increase their understanding of how to reduce emissions as an integrated way of identifying opportunity costs of environmental activities that have become important issues for stakeholders (Almihoub \& all, 2013). With the observation of the basic principles of Activity-Based Costing method (ABC), green accounting completes the terminology and the dictionary of terms used by the $\mathrm{ABC}$ method. Consequently, terms such as: activity cost driver, process cost driver, direct costs, activity cost, cost object, activity-based management, performance management, value chain, etc. are completed by other terms such as: activity-based costing system, environment cost calculation, environment management system, full environment cost calculation, green (environmental) accounting, investment management, product life cycle analysis, product life cycle calculation, logistics, pollution prevention, private costs, activity added value, etc (Capusneanu, 2008).

The enterprise is able to break down all expense functions within it and allocate them to particular areas when an ABC system is deployed. For instance, for particular manufacturing and non-manufacturing activities, waste streams, remediation programs, or any other field considered acceptable, all environmental, health, and safety (EHS) costs may be allocated. While several enterprises are now using $\mathrm{ABC}$ to justify EHS amelioration, most are not. The responsibility of revamping a cost accounting system to properly assign direct and indirect (overhead) costs is just too burdensome for those enterprises without ABC. On the other side, as enterprises shift from a facilityby-facility focus to a more global one and when a company makes the shift to such an enterprise wide system, ABC accounting is often employed (Vuola \& all, 2020).

It is important to determine the contribution of business activities to sustainable or green development and growth. By establishing a monetary value for sustainability, polluting activities will be highlighted and in turn relevant decisions can be taken. For instance, with ABM that identifies activities that do not add value since they have a more extensive negative than positive impact from an economic, social and environmental focus, these activities can be reduced or even eliminated. Therefore, environmental management accounting and the relevant tools may assist companies to reduce their environmental footprint by identifying negative activities. Negative activities can be minimized through the ABC and ABM processes. According to Lindskog et al. (2011), companies are increasingly interested in reducing the environmental footprint of their products and activities. By way of illustration, $\mathrm{ABC}$ may define various environmental cost drivers and then allocate the costs of a particular activity that eventually allocates environmental costs of certain products thereby indicating the true cost of a product. The use of $\mathrm{ABC}$ to decrease inputs such as materials, water, energy and non-product outputs such as waste and emissions, eco-efficiency can be created. Furthermore, when companies can determine costs more accurately, it leads to improved decisions on management, cost savings and reporting initiatives. Therefore, management accounting, more precisely ABC, will support enterprises with quality environmental decisions (Van, 2014). 
Căpusneanu (2008) dealt with opportunities for application of green accounting to the activitybased costing method and clarified activity-based costing and differences between this method and traditional methods. Green accounting follows the ABC method and it mentions the role of environmental accounting and the application of environmental accounting to each specific activity. It also represents advantages and disadvantages of green accounting in an enterprise applying the $\mathrm{ABC}$ method. The $\mathrm{ABC}$ method helps the accountant to assess more precisely the real cost of production and the environmental effects of each activity ( $\mathrm{Tu} \&$ all, 2019). Moreover, the use of ABC as an environmental management accounting approach can support the development of more accurate information about sustainability and emissions' reductions (Almihoub \& all, 2013).

\section{The Cãpusneanu Model}

The Cãpusneanu model, as its name implies, is a research was carried out by Cãpusneanu (2008) which focuses on the role of $\mathrm{ABC}$ in green accounting. According to this model, Green accounting which observes $\mathrm{ABC}$ method principles helps to measure saving costs as a result of reducing raw materials cost during the recycling or reusing period. As a consequence, $\mathrm{ABC}$ or $\mathrm{ABM}$ method provides an approach to look at opportunities of designing costs of the main environmental activities. The environmental cost design represents the concept that refers to the design of an environmental target cost oriented product or constraints, such as the design terms of de-assembling a product. Recycling design refers to the product design concept that emphasizes the facility of de-assembling and recycling, as well as the end of a product's useful life cycle. The usefulness and advantages of activity-based costing method can be revealed by green accounting. The application of the ABC method principles is recommended for prompting environment improvement results (Capusneanu, 2008).

The $\mathrm{ABC}$ method proceeds to allocate costs to processes and further on to activities. Environmental elements must be added at the activity level. The ABM method uses information provided by the ABC method for making decisions. In such case, the addition of environmental information is necessary for making much more accurate and efficient long term decisions. So, the $\mathrm{ABC}$ method becomes a very efficient tool of management accounting that identifies the real production costs and offers an impetus for improving ongoing processes in the enterprise or even re-engineering that is not necessarily based on traditional accounting systems (which does not reveal the environment costs).

According Cãpusneanu, The itinerary which must be followed for implementing green accounting consists of the following stages (Capusneanu, 2008):

\section{Stage 1: Setting up The Objectives of Green Accounting}

There are multiple objectives of green accounting. Among them: identifying, collecting, calculating and analyzing material and energy-related costs; internal reporting and using information about environmental costs; providing other cost-related information in the decision process, with a view to adopting efficient decisions and contributing to environment protection; about the financial performance of the organization and green accounting, providing useful information for reaching cost minimization targets (especially environment) and negative impact on environment, presenting data about costs necessary for estimating the financial impact of such initiatives.

\section{Stage 2: Setting Up The Green Accounting project Team And Project Running}

In this stage, the green accounting project team will be appointed by the company management and will be made up of specialists from the management accounting department and environment specialists. The team project will incorporate five members and a project chief. Initially, the team will analyze the following matters: 


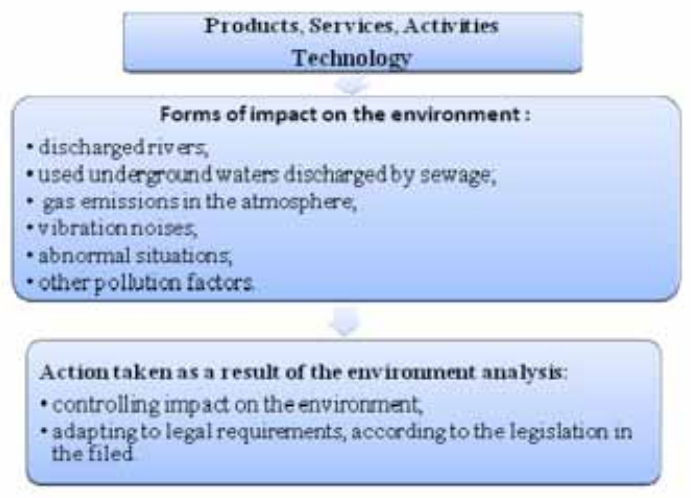

The following figure shows the environmental analysis according to ABC method:

1. Identifying the significant influences of the enterprise on the environment as identifying highly polluting sources with negative impact on the environment, characteristics of environment performances, etc.

2. Determining the forms of impact on the environment and the elements of environment analysis such as products, services, activities, processes and technologies. The chart below presents both the environment analysis elements and the identified forms of impact, including action taken as a result of the environment analysis.

3. Defining the environmental costs: The United Nations Division for Sustainable Development describes environmental costs as environmental protection costs (emission treatment and pollution prevention), including waste material costs or investment cost and wasted labor. In this context, waste refers to production inefficiency (added value or non material output). The next step will consist of questioning the departments according to processes, and within the processes, the specific environmental activities. A preliminary dictionary of the most significant environment-specific activities will be prepared based on questionnaires obtained from enterprise employees. Also information will be collected about allocation units of environment-specific costs (environmental cost drivers). At this stage, a list of specific environmental activities could be prepared, as well as other types of documents which the ABC method can provide. The chart below presents both the environment analysis elements and the identified forms of impact:

\section{Stage 3: Identification of Possible Difficulties Encountered After Covering The Two Stages and Seeking Future Opportunities}

In connection with the two aspects, a parallel report will be prepared, focusing on the following matters: Aspect no. 1, if the two stages proceeded according to plan and no problems occurred.

Aspect no 2, if problems occurred after the two stages. The deviations causes are searched. Every stage is carefully analyzed and the causes which lead to the problems are tracked down, using different specific diagnosis methods. This stage is very important, because it represents the point which can lead us to an either successful or failed implementation of the green accounting. 


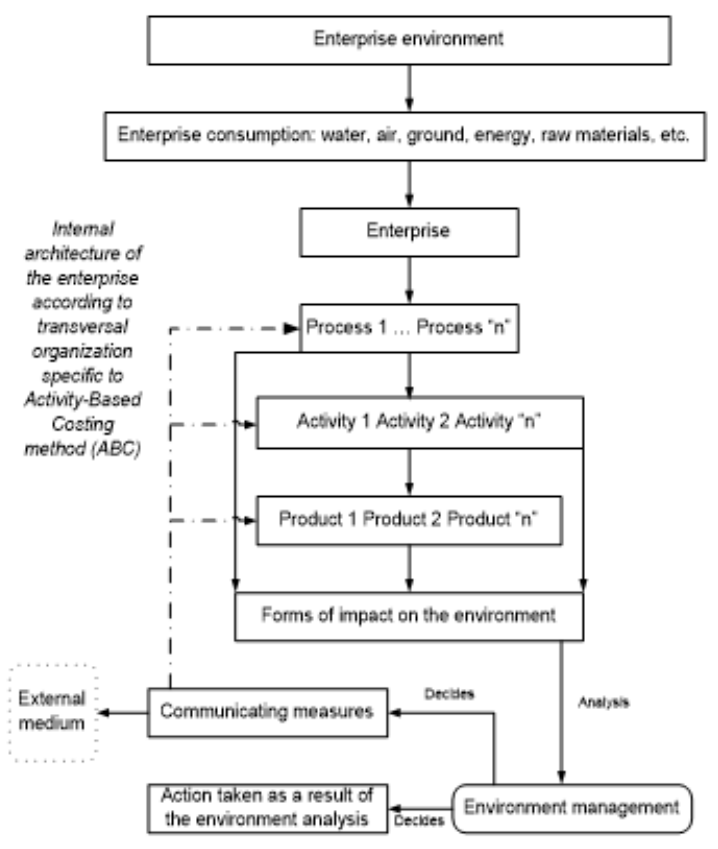

\section{Stage 4: Testing The Accurate Implementation Mode of The Green Accounting}

This is done using the information provided by the implementation process. The impact of every initiative action or project will be tested by means of cost accounting saved as a result of applying or not applying green accounting, and earnings gained by means of a correct application of activity administration principles specific to ABC method. Depending on this stage, certain changes will be made. These changes can be different in nature, such as: ecological design of products, environmental cost planning, changing the employees' attitude on environmental issues, team co-operation by changing outlooks and ideas on the efficient running of ecological activities, etc. Continuous communication and training of both employees and employers represent key factors in ensuring the successful implementation of the green accounting project.

\section{DATA AND METHODOLOGY}

This practical section seeks to link the theoretical knowledge with reality and the field practices to measure the costs of green activities in the Algerian environment. It presents the essential points in terms of the methods and tools used, including the statistical methods adopted in the analysis, and it discusses the results obtained.

\section{The Method and Tools Used in The Field Study:}

The most important steps followed in this study are stated below.

\section{Data Collection Tool}

The researchers conducted an exploratory study using a survey method (a questionnaire) to understand people's perception around the reality of business organizations' interest in the environmental 
dimension and the reality of business organizations 'interest in measuring green costs. This research is conducted in the southeast area of Algeria during the period of the first semester of 2019/2020 academic year. A number of 180 respondents are selected to participate in the study. The target sample includes accountants and those who are charged with conducting accounting business in enterprise. The primary data are collected by the administration of a well - structured questionnaire. Likert's scale (three degrees) is used. The data collected are classified and tabulated for analysis in accordance with the objectives of the study.

The questionnaire consists of two sets of statements in addition to personal and functional characteristics, totaling 20 , distributed as follows:

Job characteristics: focused on each of the position, educational level, and professional experience, and it is displayed in 03 phrases;

The first axis: it focuses on the reality of business organizations 'interest in the environmental dimension, and it covers 07 phrases;

The second axis: This part is summarized in 07 phrases about the reality of business organizations 'interest in measuring green costs;

When developing these questions, consideration was given to developing questions that cover all aspects of the theoretical study, taking into account that most of the questions are clear and have closed ends for the ease and speed of answering them and the ease of their analysis.

\section{a. Study Community and Sample:}

The study community is represented in various economic institutions with a focus on industrial institutions. It has also been emphasized that members of that community should be sufficiently informed about the subject and should have scientific and practical experience. The study includes a group of accountants and managers of economic institutions. The questions were prepared on the Rensis Likert Three-Answer Scale. After completing the final form of the questionnaire, it was distributed to the targeted sample.

\section{b. The Statistical Methods Used in The Study:}

To achieve the objectives of the study and analyze the collected data, Microsoft Excel and SPSS were used in order to extract the following statistics:

- Frequencies and percentages to show the percentages of the study sample responses;

- The reliability coefficient, Cronbach's alpha, to measure the reliability of the paragraphs and dimensions of the questionnaire;

Reliability of the study tool:In order to ensure the reliability of the study tool and the validity of the individuals 'answers for the analysis, the Cronbach's alpha coefficient is calculated, as this parameter takes values ranging from zero indicating lack of stability and one indicating complete reliability. Its estimates were shown in the following table 1 :

The above table shows that the Cronbach alpha values for the two axes are generally acceptable, since the ratio is more than $70 \%$, which indicates that the questionnaire has a high degree of reliability, and it should be noted that the validity factor is more than $83 \%$.

Presentation and analysis of results: After determining the characteristics of the sample and based on their answers, the results obtained were analyzed through the use of descriptive statistics. 
Table 1. The Cronbach's alpha

\begin{tabular}{|c|l|l|l|l|l|}
\hline Construct & N. of items & \multicolumn{1}{|c|}{$\begin{array}{c}\text { Cronbach's } \\
\text { alpha }\end{array}$} & \multicolumn{1}{|c|}{ Validity } & Description & Meaning \\
\hline Axis 1 & 07 & 0.741 & 0.861 & $\begin{array}{l}\text { More than } \\
70 \%\end{array}$ & $\begin{array}{l}\text { Reliability is } \\
\text { good }\end{array}$ \\
\hline Axis 2 & 07 & 0.698 & 0.835 & \\
\hline
\end{tabular}

Source: Prepared by researcher from the SPSS output.

Description of the characteristics of the study sample: This study is based on a number of variables related to the functional and personal characteristics of the study sample individuals as follows:

The table above shows the distribution of the study sample individuals according to a number of functional variables related to the study sample, that sample was distributed as follows:

- The position category to which the respondents belong, it is noticed that the study sample varied between managers and accountants because the study related to the accounting aspect and the decision-makers in the enterprise.

- The professional experience category of the sample members varied, but the majority of them had more than 6 years of experience, and this allows giving answers that are far-sighted and valuable.

- Regarding the educational level category, the majority of the sample members have a university level with varying degrees of education, thus it can be said that the respondents are suitably scientifically qualified, which can be deemed as a good indicator of the accuracy of the results that will be reached later.

The reality of business organizations 'interest in the environmental dimension:

Table 2. The Characteristics of the Participants

\begin{tabular}{|c|c|c|c|}
\hline Characteristics & Classification & No. of respondents & Percentage \\
\hline \multirow{3}{*}{ Position } & Accountant & 75 & $41.67 \%$ \\
\hline & Manager & 105 & $58.33 \%$ \\
\hline & Total & 180 & $100 \%$ \\
\hline \multirow{5}{*}{$\begin{array}{c}\text { Professional } \\
\text { experience }\end{array}$} & Less than 5 yrs. & 10 & $16.67 \%$ \\
\hline & Between 6 and $10 \mathrm{yrs}$ & 19 & $31.67 \%$ \\
\hline & Between 11 and $15 \mathrm{yrs}$ & 9 & $15 \%$ \\
\hline & More than & 22 & $36.66 \%$ \\
\hline & Total & 180 & $100 \%$ \\
\hline \multirow{5}{*}{$\begin{array}{c}\text { Educational } \\
\text { level }\end{array}$} & Diploma & 54 & $30 \%$ \\
\hline & Bachelor & 84 & $46.67 \%$ \\
\hline & Master & 30 & $16.67 \%$ \\
\hline & $\mathrm{PhD}$ & 12 & $6.66 \%$ \\
\hline & Total & 180 & $100 \%$ \\
\hline
\end{tabular}

Source: Prepared by researcher from the SPSS output. 
Table 3. Statistical indicators of respondent's opinions about the reality of business organizations 'interest in the environmental dimension

\begin{tabular}{|c|l|l|l|l|}
\hline \multirow{2}{*}{ Paragraphs } & \multicolumn{3}{|c|}{ Percentage } & \multirow{2}{*}{ Mode } \\
\cline { 2 - 4 } & \multicolumn{1}{|c|}{ Great } & \multicolumn{1}{|c|}{ Medium } & \multicolumn{1}{c|}{ Weak } & \\
\hline $\mathbf{1}$ & $15.00 \%$ & $40.00 \%$ & $45.00 \%$ & Weak \\
\hline $\mathbf{2}$ & $11.66 \%$ & $41.67 \%$ & $46.67 \%$ & Weak \\
\hline $\mathbf{3}$ & $6.67 \%$ & $33.33 \%$ & $60.00 \%$ & Weak \\
\hline $\mathbf{4}$ & $16.67 \%$ & $26.66 \%$ & $56.67 \%$ & Weak \\
\hline $\mathbf{5}$ & $5.00 \%$ & $36.67 \%$ & $58.33 \%$ & Weak \\
\hline $\mathbf{6}$ & $13.33 \%$ & $20.00 \%$ & $66.67 \%$ & Weak \\
\hline $\mathbf{7}$ & $8.33 \%$ & $36.67 \%$ & $55.00 \%$ & Weak \\
\hline Total & $10.95 \%$ & $33.57 \%$ & $55.48 \%$ & Weak \\
\hline
\end{tabular}

Source: Prepared by researcher from the SPSS output.

The table below shows the percentages of the various degrees of the sample responses around of the reality of business organizations' interest in the environmental dimension, and after statistical treatment, the following result is reached:

The most important results presented in this table concerning the percentages of the various categories of responses and the mode corresponding to each paragraph are restated below:

The responses of the various members of the sample were distributed between the large degree (approval), the medium degree, and the weak degree (disapproval). However, it can be observed that the direction of the answers to the various paragraphs goes towards disagreement. This result explains the weak score that approaches or exceeds $50 \%$ in most of the responses of the participants. And this was reflected through the mode that expresses the degree of responses; the highest frequency, which was within the weak degree;

Concerning the total axis of the individuals' responses about the seven paragraphs in total, the highest percentage is within the weak score at $55.48 \%$, followed by the medium grade by $33.57 \%$, and finally the large degree by $10.95 \%$. For the sake of clarification, the distribution of responses of the total axis is represented through the following sector graph:

Figure 3. A graphic of respondent's opinions about the reality of business organizations interest in the environmental dimension.

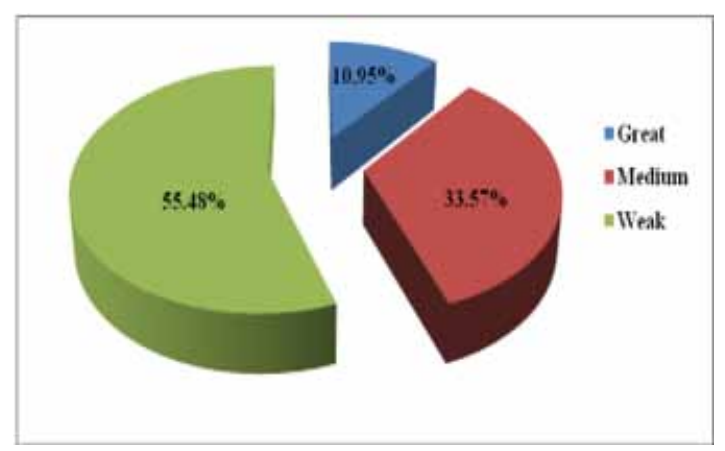

Source: Prepared by researcher from the EXEL output. 
Table 4. Statistical indicators of respondent's opinions about the reality of interest of business organizations in measuring green costs by $A B C$ or another system

\begin{tabular}{|c|l|l|l|l|}
\hline \multirow{2}{*}{ Paragraphs } & \multicolumn{2}{|c|}{ Percentage } & \multirow{2}{*}{ Mode } \\
\cline { 2 - 4 } & \multicolumn{1}{|c|}{ Great } & \multicolumn{2}{c|}{ Medium } & Weak \\
\hline $\mathbf{1}$ & $5.00 \%$ & $23.33 \%$ & $71.67 \%$ & Weak \\
\hline $\mathbf{2}$ & $3.33 \%$ & $20.00 \%$ & $76.67 \%$ & Weak \\
\hline $\mathbf{3}$ & $1.67 \%$ & $15.00 \%$ & $83.33 \%$ & Weak \\
\hline $\mathbf{4}$ & $3.33 \%$ & $21.67 \%$ & $75.00 \%$ & Weak \\
\hline $\mathbf{5}$ & $6.67 \%$ & $16.67 \%$ & $76.67 \%$ & Weak \\
\hline $\mathbf{6}$ & $5.00 \%$ & $13.33 \%$ & $75.67 \%$ & Weak \\
\hline $\mathbf{7}$ & $6.67 \%$ & $18.33 \%$ & $77.14 \%$ & Weak \\
\hline Total & $4.53 \%$ & $18.33 \%$ & & Weak \\
\hline
\end{tabular}

Source: Prepared by researcher from the SPSS output.

The reality of business organizations 'interest in measuring green costs by $\mathrm{ABC}$ :

The table below displays the percentages of the various degrees of the sample's answers about the reality of interest of business organizations in measuring green costs by $\mathrm{ABC}$ or another system. After statistical treatment, the following resultsare reached:

Through the results presented in the above table in terms of percentages for the various categories of responses and the mode corresponding to each paragraph, the most important results are examined below:

The responses of the various members of the sample varied between the large degree (approval), the medium degree, and the weak degree (disapproval), but it can be seen that most of the answers for the various paragraphs tended towards disagreement and this explains the weak score that exceeded $75 \%$ in most of the responses. This is reflected through the mode that expresses the degree of responses; the highest frequency, which was within the weak degree;

Regarding the total axis of individuals' responses around the seven paragraphs in total, the

Figure 4. A graphic of respondent's opinions about the reality of interest of business organizations in measuring green costs by $A B C$ or another system

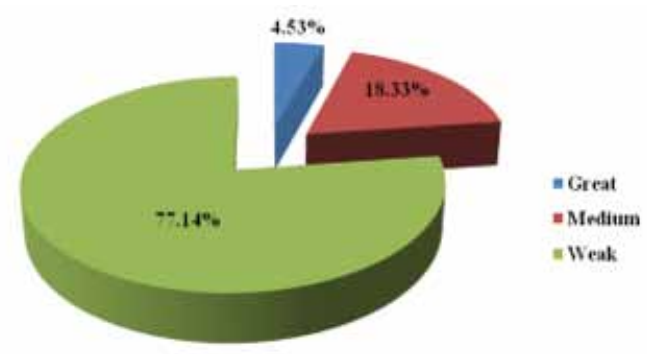

Source: Prepared by researcher from the EXEL output. 
highest percentage is within the weak score by $77.14 \%$, followed by the medium degree by $18.33 \%$, and finally the large degree by $04.53 \%$. To elucidate, the distribution of responses of the total axis is represented through the following sector graph:

Analysis and discussion of results:

Based on the data obtained from the statistical study of the reality of business organizations 'interest in the environmental dimension, the following results can be reached:

Lack of the overall vision of business organizations regarding the environmental dimension; Loss of market opportunities that could be achieved by offering environmentally friendly products; Lack of attention paid to promoting environmental awareness among workers;

Lack of concrete interest in the efficient use of resources to ensure the preservation of nature; Low interest in higher administrative levels in environmentally friendly production systems; Lack of attention to preventive measures to reduce environmental pollution;

Weak interest in providing products and services that have environmental value.

Thus the following point can be reached:

Weak interest of organizations in the environmental dimension, according to the study sample.

Through the results of the statistical study of business organizations interest in measuring green costs, we can conclude the following:

Weakness of the accounting information system for business organizations, which takes into account the measurement of costs of activities that in turn, would prevent harm to the environment;

The accounting system for business organizations neglects the measurement of the costs of monitoring activities for potential sources of environmental damage;

The accounting system in business organizations according to the study sample does not take into account mainly the measurement of the costs of green activities related to the control and control of materials used in production processes;

Accounting information systems for enterprises, according to the study sample, are not concerned with measuring the costs of activities related to identifying and assessing environmental damage, if they occur.

There is a belief among business organization managers that the financial burdens of green cost accounting outweigh its benefits;

The attention to the analysis of environmental costs in business organizations is not considered as an aid in avoiding the obligations that arise due to a breach in environmental protection, since the economic systems and consumers do not attach sufficient importance to protecting the environment and therefore there are no significant obligations when violating the protection of the environment.

Therefore, the following conclusion can be generated:

There is a weak interest of business organizations in measuring green costs (environmental). 


\section{REFERENCES}

Abdullah, M., \& Yuliana, A. (2018). Corporate Environmental Responsibility: An Effort To Develop A Green Accounting Model. Jurnal Akuntansi, 22(3), 305-320. doi:10.24912/ja.v22i3.390

Agarwal, V., \& Kalpaja, L. (2018). A study on the importance of green accounting. International Journal of Advance Research. Ideas and Innovations in Technology, 4(5), 206-210.

Almihoub, A., Mula, J. M., \& Rahman, M. (2013). Are there effective accounting ways to determining accurate accounting tools and methods to reporting emissions reduction? Journal of Sustainable Development, 6(4), $118-129$.

Aruna, S., \& Venkataswamy, R. (2018). Academic Workbench for Streetlight Powered by Solar PV System Using Internet of Everything (IoE). In 2018 International Conference on Communication, Computing and Internet of Things (IC3IoT). IEEE. doi:10.1109/IC3IoT.2018.8668152

Avis, J., Burke, L., \& Wilks, C. (2009). Management Accounting Decision Management. Elsevier.

Bogdănoiu, C. L. (2009). Activity based cost from the perspective of competitive advantage. Journal of Applied Economic Sciences, 4(07), 5-11.

Capusneanu, S. (2008). Implementation opportunities of green accounting for activity-based costing (ABC) in Romania. Theoretical and Applied Economics, 1(518), 57-62.

Kaplan, R. S., \& Cooper, R. (1998). Cost and effect: Using integrated cost systems to drive profitability and performance. Harvard Business School Press.

Loiseau, E., Saikku, L., Antikainen, R., Droste, N., Hansjürgens, B., Pitkänen, K., Leskinen, P., Kuikman, P., \& Thomsen, M. (2016). Green economy and related concepts: An overview. Journal of Cleaner Production, 139, 361-371. doi:10.1016/j.jclepro.2016.08.024

Pramitari, I., Sudiadnyani, I., \& Abdi, N. (2019). Green Accounting Based on University Social Responsibility at Politeknik Negeri Bali. In International Conference On Applied Science and Technology 2019-Social Sciences Track (iCASTSS 2019). Atlantis Press. doi:10.1007/978-3-030-00440-8_8

Rahmane, A., Zergoune, M., \& Lazhar, A. (2019). Green entrepreneurship in the Algerian renewable energy sector: Opportunities and challenges. Dirassat Journal Economic Issue, 10(1), 349-364.

Rajshree, R., \& Vangara, S. (n.d.). Need of Green Accounting. IOSR Journal of Business and Management, 4, 39-43.

Rimer, A. E. (2000). Identifying, reducing, and controlling environmental costs. Plant Engineering, 54(3), $114-118$.

Rounaghi, M. M. (2019). Economic analysis of using green accounting and environmental accounting to identify environmental costs and sustainability indicators. International Journal of Ethics and Systems, 35(4), 504-512. doi:10.1108/IJOES-03-2019-0056

Roztocki, N., Porter, J. D., Thomas, R. M., \& Needy, K. L. (2004). A procedure for smooth implementation of activity-based costing in small companies. Engineering Management Journal, 16(4), 19-27. doi:10.1080/104 29247.2004.11415262

Ryszawska, B. (2019). The Role of CSR in the Transition to a Green Economy. In Corporate Social Responsibility. Springer.

Sachin, M., \& Sandeep, N. (2019). Development of green Operation framework for Automotive part Manufacturing Companies. Asian Journal of Management, 10(4), 335-342. doi:10.5958/2321-5763.2019.00050.7

Shukla, A., \& Bhamre, M. (2017). An Indian Policy Review and Success Stories on Sustainable \& Green Economy. CnR's. International Journal of Social Science Research, 3(2), 35-40.

Sinha, V. C. (2020). Business environment. SBPD Publishing House.

Steven Landefeld, J., \& Hines, J. R. (1985). National Accounting For Non-Renewable Natural Resources In The Mining Industries. Review of Income and Wealth, 31(1), 1-20. doi:10.1111/j.1475-4991.1985.tb00495.x 
Stoicea, P. (2012). Environment management accounting in Romania companies operating in rural tourism. International Journal of Energy and Environment, 6(1), 125-133.

Tu, C. A., Hai, P. T., Hanh, H. T., \& Minh, N. B. (2019). Strengthening the Application of Management Accounting to Improve Operational Efficiency at Vietnamese Enterprises. Academy of Accounting and Financial Studies Journal, 23(3), 1-15.

Turney, P. B. (1992). Activity-based management: ABM put ABC information to work. Management Accounting, 73(7), 1992.

Unnithan, K. V., \& Somasundaram, M. A. (2019). study on the concepts and importance of green accounting in india. Compliance Engineering Journal, 10(10), 221-229.

Van Der Poll, H. M. (2014). Facilitatinga greener environment through management accounting. African Journal of Hospitality, Tourism and Leisure, 4, 1-15.

Vijayalakshmi, V., Harishkumar, M., \& Harishkumar, M. (2019). A study on the significance of emerald accounting. Seshadripuram Journal of Social Sciences, 2(1), 92-100.

Vuola, M., Korkeakoski, M., Vähäkari, N., Dwyer, M. B., Hogarth, N. J., Kaivo-oja, J., Luukkanen, J., Chea, E., Thuon, T., \& Phonhalath, K. (2020). What is a Green Economy? Review of National-Level Green Economy Policies in Cambodia and Lao PDR. Sustainability, 12(16), 1-20. doi:10.3390/su12166664

Weygandt, J. J., Kimmel, P. D., \& Kieso, D. E. (2018). Managerial accounting: tools for business decision making. John Wiley \& Sons. 